\title{
LA ALTERACIÓN DE LA SALUD DEL TRABAJADOR COMO FACTOR DE DISCRIMINACIÓN EN LAS RELACIONES LABORALES: DISCAPACIDAD Y ENFERMEDAD
}

\author{
Patricia Orlanda Rodríguez Padrón \\ $\frac{\text { alu0100889864@ull.edu.es }}{\text { Universidad de La Laguna }}$
}

\section{RESUMEN}

El concepto de discapacidad, no unitario en nuestro ordenamiento jurídico, se encuentra en constante evolución, y prueba de ello es la reciente jurisprudencia del TJUE, que en el ámbito de la ocupación y el empleo ha supuesto la configuración de un concepto flexible de discapacidad, que permite extender la protección jurídica de la Directiva 2000/78/CE del Consejo, de 27 de noviembre de 2000, relativa al establecimiento de un marco general para la igualdad de trato en el empleo y la ocupación, a aquellos trabajadores/as que padezcan dolencias que, pese a no ser calificadas administrativamente como discapacidad, sean acreedoras de esta especial tutela. Esta doctrina supone una novedad, ya que, aun circunscrita a las relaciones laborales, se abandona la concepción tradicional de la discapacidad como situación permanente e irreversible.

Palabras clave: discapacidad, enfermedad, discriminación, ajustes razonables.

\section{ALTERING WORKERS' HEALTH AS A FACTOR OF DISCRIMINATION IN EMPLOYMENT RELATIONSHIPS: DISABILITY AND ILLNESS}

\section{Abstract}

The concept of disability, which is not unitary in our legal system, is in constant evolution, and proof of this is the recent jurisprudence of the TJUE, which in the field of occupation and employment, has meant the configuration of a flexible concept of disability, which allows for the extension of the legal protection of Council Directive 2000/78/EC, of 27 November 2000, relating to the establishment of a general framework for equal treatment in employment and occupation, to those workers who suffer from ailments which, despite not being administratively classified as a disability, are worthy of this special protection. This doctrine is a novelty since, even though it is limited to labour relations, it abandons the traditional conception of disability as a permanent and irreversible situation.

KeYwords: Disability, Ilness, Discrimination, Reasonable Adjustments. 


\section{INTRODUCCIÓN}

Las personas con discapacidad constituyen un colectivo que ha sido históricamente discriminado y excluido, especialmente en lo que se refiere a su incorporación y permanencia en el mercado de trabajo, en el cual siempre se han desenvuelto con especiales dificultades. Consciente de ello, la Directiva 2000/78/CE, de 27 de noviembre de 2000 , relativa al establecimiento de un marco general para la igualdad de trato en el empleo y la ocupación (DOUE-L-2000-82357, de 2 de diciembre de 2000), ha centrado parte de sus esfuerzos en la lucha contra la discriminación por razón de discapacidad en las relaciones laborales. Y ello, por considerar que «el empleo y la ocupación son elementos esenciales para garantizar la igualdad de oportunidades para todos y contribuyen decisivamente a la participación plena de los ciudadanos en la vida económica, cultural y social, así como a su desarrollo personal» (cfr. su considerando octavo). A tal fin, la referida norma articula un sistema que, además de proteger a los trabajadores/as frente a tratamientos discriminatorios, les brinda la oportunidad de que se implanten todas aquellas medidas de adaptación del puesto de trabajo que resulten más adecuadas.

En los últimos años, por parte tanto de la doctrina científica como de la propia jurisprudencia laboral, se ha valorado la posibilidad de que la enfermedad, como situación fronteriza con la discapacidad, sea merecedora de la especial tutela antidiscriminatoria con que cuenta el trabajador con discapacidad. Precisamente a raíz de los recentísimos pronunciamientos del Tribunal de Justicia de la Unión Europea, en adelante TJUE, se ha constatado la necesidad de construir un nuevo concepto de discapacidad, que -sentado sobre las bases del modelo social- permita la inclusión de aquellas enfermedades que, aun no respondiendo a la concepción tradicional de la discapacidad, supongan una limitación para el adecuado desarrollo de su puesto de trabajo.

Las personas con discapacidad gozan de un sólido marco jurídico protector, tanto a nivel europeo como nacional. Un recorrido por la normativa existente a lo largo de la historia refleja la evolución que ha tenido lugar en cuanto a la forma de concebir el fenómeno de la discapacidad, de modo que, aunque inicialmente se ponía el foco de atención en la superación de la dolencia, actualmente se centran gran parte de los esfuerzos en la adopción de toda clase de medidas que posibiliten la integración social de las personas con discapacidad. De este modo, se observa que las primeras normas reguladoras de la materia responden al denominado modelo médico rehabilitador, para el que -configurando la discapacidad desde una perspectiva individualista- la solución pasaba por el tratamiento médico enfocado en la disminución o eliminación de la discapacidad, sin que se haga alusión a ningún instrumento dirigido a posibilitar la plena inserción en la sociedad ni a la responsabilidad del Estado en la consecución de dicha labor. De igual modo, la construcción del concepto de discapacidad ha sido fruto de una larga evolución empleándose diversos términos para hacer referencia a la misma, entre la contundencia descriptiva y el eufemismo (Pérez, 2015: 91).

Una de las primeras normas dictadas en la materia es la Orden de 7 de noviembre de 1968, por la que se conceden ayudas a centros de empleo protegido 
para trabajadores minusválidos ( $B O E$ núm. 288, de 30 de noviembre), que, como ejemplo paradigmático de la plasmación del modelo médico, no articula ningún mecanismo de inclusión ni medidas de adaptación por parte de las empresas. De este modo, la norma se limita a constatar la imposibilidad de incorporación al mercado laboral en el régimen ordinario, quedando limitada la prestación de trabajo al ámbito de los centros de empleo protegido. En el artículo primero del citado cuerpo legal se acuña el hoy ya abandonado concepto de "minusválido», en el que se incluye «todo trabajador en edad laboral, considerándose como tal la comprendida entre los dieciocho y los sesenta y cinco años que, encontrándose en situación de desempleo, se vea además afectado por una disminución de su capacidad física superior a un 30 por 100 que le impida el acceso a puestos de trabajo en Empresas de régimen de trabajo normal precisamente a causa de tal merma de capacidad». El campo protector de la norma se circunscribe, por tanto, a las personas que acrediten un grado superior de discapacidad. Dos años más tarde, por obra del Decreto 2531/1970, de 22 de agosto, sobre empleo de trabajadores minusválidos (BOE núm. 221, de 15 de septiembre), comienza tímidamente la transición hacia el denominado modelo social que, orientado desde una perspectiva colectiva, se centra en la adopción de medidas de integración de las personas con discapacidad, proponiendo que sea la sociedad la que deba brindarles todos los instrumentos necesarios a fin de facilitar la inserción social. De nuevo, esta norma condiciona la adquisición del estatus de persona con discapacidad a la constatación del grado que reglamentariamente se determine, sin que en ningún caso pueda ser inferior al 33 por 100.

A partir de la aprobación de la Constitución española de 1978, en adelante $\mathrm{CE}$, se consolida el modelo social de protección de las personas con discapacidad, incluyéndose en su articulado una mención expresa al referido colectivo junto con un claro mandato a los poderes públicos. Se trata del artículo 49 de la CE, el cual dispone que «los poderes públicos realizarán una política de previsión, tratamiento, rehabilitación e integración de los disminuidos físicos, sensoriales y psíquicos a los que prestarán la atención especializada que requieran y los ampararán especialmente para el disfrute de los derechos que este Título otorga a todos los ciudadanos». Dicho mandato constitucional debe ser puesto en relación con el artículo 9.2 de la propia $\mathrm{CE}$, en virtud del cual «corresponde a los poderes públicos promover las condiciones para que la libertad y la igualdad del individuo y de los grupos en que se integra sean reales y efectivas; remover los obstáculos que impidan o dificulten su plenitud y facilitar la participación de todos los ciudadanos en la vida política, económica, cultural y social». En definitiva, deben promoverse las condiciones necesarias para garantizar la igualdad de las personas con discapacidad, consideradas individualmente. Como puede observarse, el lenguaje empleado por el legislador -a mi juicio, poco afortunado- supone un cierto anacronismo respecto a la normativa precedente, toda vez que continúa utilizando el término «disminuido».

La aprobación de la Ley 13/1982, de 7 de abril, de Integración Social de los Minusválidos ( $B O E$ núm. 103, de 30 de abril), en adelante LISMI, supone un verdadero punto de inflexión, visto que constituye la primera norma que contiene una regulación integral en materia de inserción de las personas con discapacidad en los distintos ámbitos de la sociedad. No obstante, no se elabora un concepto de dis- 
capacidad genérico que integre todo el sistema jurídico, limitándose su alcance al estricto ámbito de la ley. De este modo, el artículo 7 de la referida norma dispone lo siguiente: «A los efectos de la presente Ley se entenderá por minusválidos toda persona cuyas posibilidades de integración educativa, laboral o social se hallen disminuidos como consecuencia de una deficiencia, previsiblemente permanente, de carácter congénito o no, en sus capacidades físicas, psíquicas o sensoriales». En su momento, esta definición dio lugar a serias dudas interpretativas, en tanto no se precisaba en ella qué grado de discapacidad hacía a una persona acreedora de la protección otorgada por la ley; cosa, por cierto, que sí se había hecho en normas anteriores, pudiendo entenderse que encuentran encaje en la norma aquellas personas cuya disminución de las posibilidades de integración resulte significativa, de modo que evidencien un desajuste merecedor de corrección (Pérez, 2015: 154). Si bien la LISMI aún se encontraba incardinada dentro del modelo médico, orientado a la superación de las deficiencias, se entendía que la inclusión social que se desarrolla por la educación y el trabajo debía ser un proceso integral, flexible y dinámico (García, 2019: 4), de ahí que se estableciese la obligación de los empresarios de «adoptar las medidas adecuadas para la adaptación del puesto de trabajo y la accesibilidad de la empresa, en función de las necesidades de cada situación concreta, con el fin de permitir a las personas con discapacidad acceder al empleo, desempeñar su trabajo, progresar profesionalmente y acceder a la formación, salvo que esas medidas supongan una carga excesiva para el empresario" (artículo 37 bis LISMI).

Más adelante, la Ley 51/2003, de 2 de diciembre, de Igualdad de oportunidades, no discriminación y accesibilidad universal de las personas con discapacidad (BOE núm. 289, de 3 de diciembre), en adelante LIONDAU, supone el regreso al criterio cuantitativo, supliendo el vacío conceptual que supuso la LISMI en cuanto a la determinación del grado de discapacidad exigible. En su artículo 1.2, se contiene una definición indirecta de discapacidad (Pérez, 2015: 162) al disponer que tienen tal carácter aquellas personas «que presenten deficiencias físicas, mentales, intelectuales o sensoriales a largo plazo que, al interactuar con diversas barreras, puedan impedir su participación plena y efectiva en la sociedad, en igualdad de condiciones con los demás». Continúa diciendo el mismo artículo 1.2 que, a los efectos de esta Ley, «tendrán la consideración de personas con discapacidad aquellas a quienes se les haya reconocido un grado de discapacidad igual o superior al 33 por ciento». De la propia configuración del citado precepto se desprende que se trata de una conceptualización limitada al estricto ámbito de aplicación de esta ley, desaprovechándose de nuevo la oportunidad de crear un concepto de discapacidad que integre todo el sistema. 


\section{MARCO JURÍDICO DE PROTECCIÓN FRENTE A LA DISCRIMINACIÓN POR RAZÓN DISCAPACIDAD EN EL ÁMBITO DE LAS RELACIONES LABORALES}

En el plano europeo, el artículo 10 del Tratado de Funcionamiento de la Unión Europea proclama que «la Unión tratará de luchar contra toda discriminación por razón de sexo, raza u origen étnico, religión o convicciones, discapacidad, edad u orientación sexual» (DOUE-Z-2010-70002, de 30 de marzo). A partir de la década de los noventa del siglo pasado, se comienza a demandar por parte de algunos sectores una ampliación de los supuestos amparados por la normativa sobre prohibición de discriminación; y entre ellos, la discapacidad. En el año 2000, como respuesta a la referida demanda, se aprueba la Directiva 2000/78/CE del Consejo, de 27 de noviembre, relativa al establecimiento de un marco general para la igualdad de trato en el empleo y la ocupación, cuyo considerando decimoprimero reconoce que «la discriminación por motivos de religión o convicciones, discapacidad, edad u orientación sexual puede poner en peligro la consecución de los objetivos del Tratado CE, en particular el logro de un alto nivel de empleo y de protección social, la elevación del nivel y de la calidad de vida, la cohesión económica y social, la solidaridad y la libre circulación de personas».

En particular, el artículo 3 de la Directiva citada concreta que sus disposiciones serán de aplicación -entre otras materias- a las condiciones de acceso al empleo, a la actividad por cuenta propia y al ejercicio profesional, al acceso a la formación profesional, a las condiciones de empleo y trabajo y a la afiliación y participación en una organización de trabajadores/as o de empresarios/as. Conviene advertir que la Directiva no desarrolla un concepto de discapacidad; como tampoco existe una remisión al derecho interno de los Estados miembros a fin de definir dicho concepto. Precisamente por ello, ha sido el TJUE -como en tantas otras ocasiones- el que ha asumido la labor de delimitar el contenido y alcance del concepto de discapacidad, debiendo los estados miembros aplicarlo de forma homogénea. En este sentido, la jurisprudencia europea, tal y como se analizará con mayor profundidad más adelante, ha asumido el concepto elaborado por la Convención sobre los Derechos de las Personas con Discapacidad, hecha en Nueva York el 13 de diciembre de 2006 (BOE núm. 96, de 21 de abril de 2008), que define la discapacidad como una situación que «resulta de la interacción entre las personas con deficiencias y las barreras debidas a la actitud y al entorno que evitan su participación plena y efectiva en la sociedad, en igualdad de condiciones con las demás» (preámbulo de la citada Convención, letra e).

La Directiva 2000/78/CE se traspuso a nuestro ordenamiento jurídico a través de la Ley 62/2003, de 30 de diciembre, de medidas fiscales, administrativas y del orden social ( $B O E$ núm. 313, de 31 de diciembre). Esto se tradujo, fundamentalmente, en la modificación del Estatuto de los Trabajadores/as, en adelante ET; y más en concreto, de su artículo 4.2.c), donde se reconoce como derecho básico de los trabajadores/as el de «no ser discriminados directa o indirectamente para el empleo, o una vez empleados, por razones de sexo, estado civil, edad dentro de los límites marcados por esta ley, origen racial o étnico, condición social, reli- 
gión o convicciones, ideas políticas, orientación sexual, afiliación o no a un sindicato, así como por razón de lengua, dentro del Estado español». Añade el precepto que «tampoco podrán ser discriminados por razón de discapacidad, siempre que se hallasen en condiciones de aptitud para desempeñar el trabajo o empleo de que se trate ${ }^{1}$. El art. 4.2.c) del ET debe ponerse en relación con el artículo 17 del mismo cuerpo legal, donde se consagra la nulidad de los pactos o cláusulas que den lugar a situaciones discriminatorias por razón de discapacidad en el ámbito del empleo.

Sin perjuicio de todo cuanto acaba de exponerse, hoy por hoy, el marco normativo principal en relación con los derechos de las personas con discapacidad viene integrado fundamentalmente por el Real Decreto Legislativo 1/2013, de 29 de noviembre, por el que se aprueba el Texto Refundido de la Ley General de Derechos de las Personas con Discapacidad y de su inclusión social (BOE núm. 289, de 3 de diciembre), en adelante LGPD, cuyo artículo 2.a), siguiendo las directrices de la Convención de la Organización de Naciones Unidas, en adelante ONU, define la discapacidad como «una situación que resulta de la interacción entre las personas con deficiencias previsiblemente permanentes y cualquier tipo de barreras que limiten o impidan su participación plena y efectiva en la sociedad, en igualdad de condiciones con las demás». Por su parte, el artículo 4.1 de la LGPD afirma que «son personas con discapacidad aquellas que presentan deficiencias físicas, mentales, intelectuales o sensoriales, previsiblemente permanentes que, al interactuar con diversas barreras, puedan impedir su participación plena y efectiva en la sociedad, en igualdad de condiciones con los demás». Añade, además, en su apartado segundo que «a todos los efectos, tendrán la consideración de personas con discapacidad aquellas a quienes se les haya reconocido un grado de discapacidad igual o superior al 33 por ciento". La discapacidad se configura, por tanto, como un concepto jurídico que pivota sobre tres elementos fundamentales: la concurrencia de cualquier tipo de deficiencia, la existencia de barreras en la sociedad y la interacción de las deficiencias con dichas barreras. De modo que provocan discriminación por razón de discapacidad "tanto la existencia de barreras sociales como la inexistencia de medidas de apoyo de todo tipo que permitan sortear dichos obstáculos hasta que éstos se pueden eliminar» (De Fuentes, 2016: 85).

${ }^{1}$ Respecto a esta cuestión resulta conveniente destacar la STSJ de Asturias de 12 diciembre de 2008 (rec. 1431/2008), en la que se declara no apto a un trabajador para un puesto como minero, por padecer asma bronquial. De modo que la enfermedad padecida por el trabajador es incompatible con el trabajo en el interior de las minas, no siendo admisible que el empresario asuma la excesiva carga que implica el alto riesgo para la salud del trabajador. Sobre esta misma cuestión, véase la STSJ de Andalucía (Granada) de 24 junio de 2003 (rec. 294/2003). 


\section{MECANISMOS DE PROTECCIÓN EN FAVOR DE LAS PERSONAS CON DISCAPACIDAD FRENTE A LAS SITUACIONES DE DISCRIMINACIÓN EN LAS RELACIONES LABORALES}

\subsection{LA PROHIBICIÓN DE DISCRIMINACIÓN POR RAZÓN DE DISCAPACIDAD}

El principal mecanismo de protección con el que cuentan las personas con discapacidad es la prohibición de discriminación en las relaciones laborales, de modo que se les garantice el acceso y la conservación del empleo en igualdad de condiciones que el resto de trabajadores/as. Por ello, las próximas líneas tienen por misión analizar a -a través de la casuística jurisprudencial- los motivos más frecuentemente esgrimidos por la empresa, ya sea para limitar el acceso al empleo, ya sea para dar por extinguida la relación laboral. El tratamiento desfavorable puede revestir múltiples formas y, si bien gran parte de la problemática gira en torno a las limitaciones para acceder a un puesto de trabajo ${ }^{2}$, no conviene olvidar que no siempre la situación discriminatoria consiste en una conducta concreta del empresario/a que atente contra el derecho a la igualdad del individuo. En efecto, nuestra jurisprudencia ha admitido la existencia asimismo de discriminación cuando el empresario/a no da cumplimiento a aquellas medidas de acción positiva establecidas en la legislación aplicable. En este sentido, la sentencia del Tribunal Superior de Justicia, en adelante TSJ, de Canarias (Las Palmas) de 23 de noviembre de 2018 (rec. 1024/2018) ha considerado que el hecho de incumplir la legislación de reserva de puestos de trabajo para discapacitados del $2 \%$ de la plantilla no implica exclusivamente la infracción de lo dispuesto en la LGPD (artículo 42), sino que constituye una auténtica discriminación en el acceso al empleo prohibida por los artículos 4.2.c) y 17.1 del ET. A mayor abundamiento, entiende la Sala canaria que, aunque no existan trabajadores/as con el perfil requerido por la empresa, ello no le exime del cumplimiento de las medidas excepcionales alternativas.

Sin embargo, particular atención merece la casuística jurisprudencial relativa a la extinción de la relación laboral por causa de la situación de discapacidad del trabajador/a. En este sentido resulta ineludible profundizar en la problemática que se suscitó en torno a la aplicación del artículo 52.d) del ET, donde se regula el despido objetivo por faltas de asistencia al trabajo justificadas, conforme al cual el contrato podrá extinguirse "por faltas de asistencia al trabajo, aun justificadas pero intermitentes, que alcancen el veinte por ciento de las jornadas hábiles en dos meses

2 En este sentido cabe citar la SJS de Murcia de 7 de mayo de 2018 (rec. 13/2018), en la que se limita la contratación de un trabajador con discapacidad bajo el pretexto de no haber informado acerca de su condición. El juez concluyó que no era necesario acreditar tal extremo, por lo que, con arreglo al principio de inversión del onus probandi, consideró el juzgador que existe una discriminación en el acceso al empleo. Por su parte, la SJS n. 3 de Gijón de 18 de abril de 2018 (rec. 697/2017) constata la existencia de discriminación en la resolución del contrato durante el periodo de prueba, y ello dado que la trabajadora ha aportado indicios suficientes que hacen desplazar la carga de la prueba al empresario; concretamente, que la trabajadora solicitó determinadas mejoras en el puesto de trabajo. 
consecutivos siempre que el total de faltas de asistencia en los doce meses anteriores alcance el cinco por ciento de las jornadas hábiles, o el veinticinco por ciento en cuatro meses discontinuos dentro de un periodo de doce meses». En particular, merece un especial análisis la sentencia del TJUE de 18 de enero de 2018, asunto Ruiz Conejero (C-270/16). El juzgador español fundamenta la cuestión prejudicial en la existencia de una aparente contradicción entre el citado precepto y la Directiva 2000/78/CE; y ello con base en que la normativa podría estar encubriendo un supuesto de discriminación indirecta, ya que, si bien a priori se trataba de una disposición neutra que se aplicaba por igual a todos los trabajadores/as, sin ningún tipo de distinción, se derivaba sin embargo una desventaja particular para el colectivo de personas con discapacidad. A tal efecto, entiende el TJUE que el riesgo de aplicación de este artículo es mayor en los trabajadores/as con discapacidad, al ser más propensos a acumular días de baja por las enfermedades derivadas de tal situación; no obstante, para poder concluir que nos encontramos ante un supuesto de discriminación indirecta conviene dilucidar si dicho tratamiento desfavorable se encuentra amparado por una finalidad legítima; y siempre y cuando los medios aplicados para su consecución sean adecuados, y no vayan más allá de lo necesario para alcanzar la finalidad prevista. En efecto, para el TJUE dicho precepto cuenta con la finalidad legítima de combatir el absentismo laboral, si bien será el juzgador nacional el encargado de verificar la adecuación de los medios empleados para su consecución, debiendo tener en cuenta para ello una serie de factores; entre ellos, si los umbrales numéricos establecidos en el artículo 52.d) del ET se han calculado efectivamente para paliar el absentismo, así como los costes directos e indirectos que han de soportar las empresas como consecuencia de las faltas de asistencia. Del mismo modo se debe valorar si el legislador, al configurar dicho precepto, ha omitido datos relevantes respecto al colectivo de trabajadores/as con discapacidad.

El juzgado de lo social, en adelante JS, de Cuenca concluye que hubo una clara omisión por parte del legislador, ya que en la relación de faltas de asistencia excluidas del cómputo - las bajas médicas de duración superior a 20 días, o las derivadas de tratamiento médico por enfermedad grave o cáncer, entre otras- no existe una mención expresa a las faltas de asistencia derivadas de la discapacidad del trabajador/a, y es por ello por lo que considera que dicha medida excede de lo necesario para alcanzar la finalidad de combatir el absentismo, y que los medios no son idóneos, adecuados y necesarios. La sentencia del TSJ de Castilla-La Mancha, de 10 de abril de 2019 (rec. 664/2018), ratifica este pronunciamiento y ańade que «la justificación de política social y empleo de dicho precepto no puede excluir los efectos de la discriminación indirecta por causa de su discapacidad provocados por su aplicación, pues los medios para la consecución de dicha finalidad no son los adecuados al no tomar en consideración la desventaja que su aplicación produce en las personas con discapacidad, factor de discriminación prohibido».

No está de más advertir, pese a que gran parte de la doctrina y la jurisprudencia venía poniendo de manifiesto la necesidad de abordar una reforma del art. 52.d) del ET (Rojo, 2019; De Heredia, 2019), de modo que se incluyeran las faltas de asistencia al trabajo derivadas de la situación de discapacidad, lo cierto es que también se demandaba por parte de algunos sectores la íntegra derogación del mismo. 
Como resultado de estas reivindicaciones, y especialmente tras el enorme impacto social ocasionado por la controvertida sentencia del Tribunal Constitucional, en adelante TC, 118/2019, de 16 de octubre (rec. 2960/2019), que concluía que el despido del trabajador por faltas de asistencia justificadas no vulneraba el derecho a la salud ni el derecho a la integridad física -haciendo primar el derecho a la libertad de empresa sobre los mismos ${ }^{3}$-, se produjo la derogación del precepto a través del Real Decreto Ley 4/2020, de 18 de febrero (BOE núm. 43, de 19 de febrero). La fundamentación del recién citado Real Decreto Ley pivota sobre dos ejes fundamentales. Por una parte, la adecuación de la legislación española a la jurisprudencia del TJUE, en aras de evitar que el trabajador/a se vea abocado a «una situación de gran vulnerabilidad profesional, personal y social»; y por otro, «la necesidad imperativa de evitar que se produzcan más resoluciones judiciales a nivel interno que resulten contradictorias entre sí» (Disp. 3.a del RD Ley 4/2020). En este sentido, la norma se hace eco de la más reciente jurisprudencia europea, en particular en lo que se refiere a la extensión de la tutela antidiscriminatoria a los supuestos de enfermedad, donde existe una clara divergencia de criterios, tal y como se expondrá más adelante. Es importante reseñar que se considera que el precepto no se ajusta a la doctrina europea en tanto que el artículo 52.d) del ET se aplica de forma automática - una vez que se alcancen los umbrales establecidos-, de modo que impide al juzgador llevar a cabo el juicio de adecuación de los medios y proporcionalidad de conformidad con la doctrina europea. En definitiva, la norma se dicta "para erradicar la situación susceptible de generar discriminaciones, inseguridad jurídica e incumplimiento de las obligaciones derivadas de nuestra pertenencia a la Unión Europea» (Disp. 7.a del RD Ley 4/2020).

\subsection{LA PROTECCIÓN DE LA DISCAPACIDAD A TRAVÉS DE LAS MEDIDAS DE ACCIÓN POSITIVA: LOS AJUSTES RAZONABLES}

Uno de los aspectos que, de acuerdo con la Directiva 2000/78, se tienen en consideración a fin de excluir el carácter discriminatorio de un tratamiento desfavorable es la realización de ajustes razonables por parte de la empresa. Su artículo 5 impone al empleador/a la obligación de realizar ajustes razonables, como se aprecia cuando dispone lo siguiente: «Los empresarios tomarán las medidas adecuadas, en función de las necesidades de cada situación concreta, para permitir a las personas con discapacidades acceder al empleo, tomar parte en el mismo o progresar profesionalmente, o para que se les ofrezca formación, salvo que esas medidas supongan una carga excesiva para el empresario. La carga no se considerará excesiva cuando

3 En relación con esta cuestión véase el voto particular formulado por la magistrada doña María Luisa Balaguer Callejón, en el cual defiende que la libertad de empresa o la defensa de la productividad no pueden ser antepuestas al derecho a la integridad física y moral de los trabajadores/as «ni a un valor tan esencial como es la protección de la salud humana». 
sea paliada en grado suficiente mediante medidas existentes en la política del Estado miembro sobre discapacidades». En la legislación española, el artículo 2.m) de la LGPD define los ajustes razonables como «las modificaciones y adaptaciones necesarias y adecuadas del ambiente físico, social y actitudinal a las necesidades específicas de las personas con discapacidad que no impongan una carga desproporcionada o indebida, cuando se requieran en un caso particular de manera eficaz y práctica, para facilitar la accesibilidad y la participación y para garantizar a las personas con discapacidad el goce o ejercicio, en igualdad de condiciones con las demás, de todos los derechos».

A diferencia de la normativa europea -que circunscribe la adopción de ajustes razonables al ámbito estrictamente laboral-, en la española se ha optado por un concepto más amplio que abarca todas las esferas de la vida personal. No obstante, el artículo 40.2 de la LGPD concreta la exigibilidad de esta obligación en el ámbito laboral, al disponer que «los empresarios están obligados a adoptar las medidas adecuadas para la adaptación del puesto de trabajo y la accesibilidad de la empresa, en función de las necesidades de cada situación concreta, con el fin de permitir a las personas con discapacidad acceder al empleo, desempeñar su trabajo, progresar profesionalmente y acceder a la formación, salvo que esas medidas supongan una carga excesiva para el empresario». Como puede observarse, tanto a nivel europeo como nacional, se configura un concepto genérico de ajustes razonables, sin que se precisen las concretas medidas que cabe adoptar. «La falta de determinación de las medidas de ajuste y su tipología dificulta sustancialmente la detección de los ajustes a realizar y su tipología, generándose -en abstracto- infinitas opciones de ajuste» (Gutiérrez, 2015: 21).

Para determinar cuándo las empresas están sujetas a la obligación de realizar ajustes debemos determinar primero cuándo son razonables. Respecto a este concreto extremo, la Directiva 2000/78 no proporciona ningún parámetro que permita precisar el término «razonable». Ausencia de detalle, como se ha puesto de manifiesto, que «se deba tal vez a que se trata de una Directiva, disposición comunitaria sobre un determinado aspecto que ha de ser incorporada a su Derecho por los Estados de la UE, que ha de ser respetada como nivel de exigencia mínima, pero que los países miembros, en el proceso de transposición, pueden elevar y ampliar» (Pérez, 2012: 9). La concreción de la razonabilidad del ajuste dependerá, por tanto, del desarrollo legislativo de cada ordenamiento interno. En este sentido, desde un punto de vista comparado, cabe distinguir tres tipos de planteamientos: estados que condicionan la razonabilidad de la medida al coste económico, los que la condicionan a la eficacia de la medida y los que tienen en cuenta tanto el coste económico como la eficacia (Carrasquero, 2018: 43).

En España, el artículo 66.2 de la LGPD es el que arroja un poco de luz sobre esta cuestión y nos concreta los aspectos que tenemos que considerar a fin de determinar si un ajuste es o no razonable. Se trata, fundamentalmente, del coste de la medida, del efecto discriminatorio que supone para el individuo la no adopción del ajuste, así como de la posibilidad de acceder a sistemas públicos de ayuda para sufragar los costes derivados de la adaptación. El carácter excesivo de la medida se encuentra estrechamente vinculado al concepto de ajuste razonable, en tanto en 
cuanto el hecho de que la carga resulte excesiva determinará que el ajuste pierda la consideración de razonable, configurándose, por tanto, como un límite para su adopción (Fernández, 2017: 20). La LGPD concreta cuáles son los aspectos que debemos considerar para determinar si una carga es o no excesiva para la empresa; en particular, «si es paliada en grado suficiente mediante las medidas, ayudas o subvenciones públicas para personas con discapacidad, así como los costes financieros y de otro tipo que las medidas impliquen y el tamaño y el volumen de negocios total de la organización o empresa» (artículo 40 párr. 2. ${ }^{\circ}$ LGPD). Todos estos criterios -de marcada naturaleza económica- evidencian que no estamos ante "un concepto estático ni uniforme para todo tipo de empresa» (Rodríguez Sanz, 2014: 85 y ss.), toda vez que una misma medida puede resultar excesiva para una empresa y razonable para otra, atendiendo a las circunstancias concurrentes en cada caso.

A mi juicio, el incumplimiento del deber de realizar ajustes razonables se puede considerar como una forma de discriminación autónoma, ya que, llevando a cabo una interpretación teleológica de la norma, podemos concluir que vincular la obligatoriedad de realizar el ajuste a la previa constatación de una situación discriminatoria supone atentar contra el fin fundamental perseguido por la Directiva de garantizar el acceso al empleo de las personas con discapacidad. Así pues, la negativa del empresario a realizar un determinado ajuste constituiría en sí misma una discriminación. En este sentido, conviene citar la sentencia del TSJ del País Vasco de 9 de julio de 2019 (rec. 1167/2019), en la que se declara la nulidad del despido de un trabajador/a con discapacidad que solicitó determinadas adaptaciones en su puesto de trabajo, y ello porque «el actor tenía derecho a que su situación, su estado físico, fuera tratado de forma individualizada con las necesarias adaptaciones».

Por lo que respecta a las concretas medidas de ajuste que cabe adoptar, si bien es cierto que con carácter general no se enumeran, el considerando 20 de la Directiva 2000/78 -a modo ilustrativo- dispone que entre las medidas a adoptar se encuentran las dirigidas a "acondicionar el lugar de trabajo en función de la discapacidad, por ejemplo, adaptando las instalaciones, equipamientos, pautas de trabajo, asignación de funciones o provisión de medios de formación o encuadre». Además, y como posible contenido de la medida, cabe destacar la recolocación en un puesto de trabajo adaptado a la discapacidad del trabajador/a, así como la reducción de la jornada de trabajo (sentencia del TSJ Cataluña de 9 de diciembre de 2014, rec. 6157/2014).

\subsection{La extensión de la tutela de la Directiva europea 2000/78/CE a los SUPUESTOS DE ENFERMEDAD: LA CASUÍSTICA JURISPRUDENCIAL}

La posibilidad de que un trabajador/a enfermo/a goce del mismo nivel de protección que otro con discapacidad, especialmente en materia de despido, con las consecuencias que se derivan de la declaración de nulidad, ha sido objeto de un profundo debate, tanto por parte de la doctrina como de la jurisprudencia. La interpretación del TJUE se ha ido flexibilizando a lo largo de los años, de modo que -aunque inicialmente mantenía una postura rígida y nada proclive a la equipara- 
ción entre enfermedad y discapacidad- ha tenido lugar una progresiva ampliación del concepto de discapacidad, y con ello la extensión de la tutela antidiscriminatoria a muchos trabajadores/as que con anterioridad se encontraban desamparados. Debemos considerar, como punto de partida, la sentencia del TJUE de 11 de julio de 2006, asunto Chacón Navas (C-13/05), que, respondiendo a las cuestiones prejudiciales planteadas por el JS n. ${ }^{\circ} 33$ de Madrid, valora la posibilidad de incluir en el campo de aplicación de la Directiva europea a los trabajadores/as enfermos/as. Aclara el tribunal que la enfermedad no se incluye dentro del catálogo de causas de discriminación prohibidas por la norma ni cuenta tampoco con un reconocimiento autónomo en la normativa internacional, no siendo posible la equiparación pura y simple de ambos conceptos.

Más adelante, la sentencia del TJUE de 11 de abril de 2013, asunto Ring (acumulados C-335/11 y C-337/11), dictada a propósito del despido de dos trabajadoras danesas por faltas de asistencia al trabajo derivadas de las dolencias que padecían, supone la flexibilización de esta postura, admitiéndose por vez primera la posibilidad de asimilar los conceptos de enfermedad y de discapacidad. El TJUE, asumiendo por completo el concepto de discapacidad configurado en la Convención de la ONU -la cual fue ratificada por la UE mediante decisión de 26 de noviembre de 2009 (DOUE L 23/35)-, la define como «una limitación, derivada en particular de dolencias físicas, mentales o psíquicas que, al interactuar con diversas barreras, puede impedir la participación plena y efectiva de la persona de que se trate en la vida profesional en igualdad de condiciones con los demás trabajadores», de modo que contarían con amparo legal aquellas enfermedades o dolencias que supongan tal limitación, siempre y cuando se trate de dolencias de carácter duradero. No proporcionaba, sin embargo, ningún criterio o parámetro que permitiese verificar el carácter duradero, de modo que es el juzgador interno el que debía asumir la ardua tarea de constatar si el trabajador padece o no una limitación de carácter prolongado o indefinido en el tiempo.

La sentencia del TJUE de 1 de diciembre de 2016, asunto Daouidi (C-395/15), articula una serie de indicios que orientan al juzgador a fin de valorar si una determinada dolencia tiene carácter duradero, a efectos de incluirse en el concepto de discapacidad europeo, entre ellos que «en la fecha del hecho presuntamente discriminatorio, la incapacidad del interesado no presente una perspectiva bien delimitada en cuanto a su finalización a corto plazo» o bien que «dicha incapacidad pueda prolongarse significativamente antes del restablecimiento de dicha persona». De igual modo, el juez debe servirse de todos los datos objetivos de los que disponga, y en particular de los documentos y certificados que reflejen el estado de salud del individuo.

A la luz de la jurisprudencia referenciada se constata cómo ha tenido lugar una progresiva flexibilización del concepto de discapacidad. A mi juicio, y atendiendo a la definición funcional y social de la discapacidad, se trata de una ampliación conceptual que deja atrás la configuración clásica de la discapacidad, como limitación permanente e irreversible, tradicionalmente condicionada a la acreditación de un concreto grado por parte de la Administración, desdibujando la tradicional línea divisoria entre enfermedad y discapacidad. En efecto, ahora se extiende 
a aquellas enfermedades que, sin perjuicio de su carácter temporal y curable, tienen una proyección a largo plazo que repercute negativamente en el desarrollo personal del trabajador/a. En definitiva, con carácter general el enorme salto cualitativo que ha dado la jurisprudencia europea merece una valoración positiva, si bien no conviene olvidar que los criterios facilitados por el TJUE son genéricos y se alude a múltiples conceptos jurídicos indeterminados, por lo que «la disparidad de criterios puede llegar a ser notable, lo que, podría dificultar una unificación de doctrina $y$, en definitiva, redundar negativamente en la seguridad jurídica» (De Heredia, 2016). En definitiva, es el juzgador nacional el que debe valorar en cada caso si la situación del individuo puede ser calificada como discapacidad, por lo que se hace patente su marcado carácter casuístico.

La necesidad de un concepto flexible de discapacidad, que permita extender el marco protector frente al despido a los trabajadores/as enfermos/as, surge a raíz de la reforma operada por la Ley 11/1994, de 19 de mayo, por la que se modifican determinados artículos del Estatuto de los Trabajadores, y del texto articulado de la Ley de Procedimiento Laboral y de la Ley sobre Infracciones y Sanciones en el Orden Social (BOE núm. 122, de 23 de mayo). Esta modificación legislativa supuso la desaparición del antiguo artículo 55.6 del ET, en el cual rezaba que «el despido de un trabajador que tenga suspendido un contrato de trabajo se considerará nulo si la jurisdicción competente no apreciase su procedencia», de modo que desaparecía una vía de tutela específica para aquellas personas que padecen enfermedades no reconocidas formalmente como discapacidad.

De este modo, la postura pacífica que tradicionalmente venía manteniéndose por los tribunales españoles -consolidada por nuestro Tribunal Supremo, en adelante TS - era la de considerar que el despido de un trabajador/a enfermo/a merece la calificación jurídica de improcedente, y no nulo. Y ello, con base en la productividad de la empresa, toda vez que la enfermedad es una situación «que hace que el mantenimiento del contrato de trabajo del actor no se considere rentable por la empresa» (sentencia del TS, de 23 de mayo de 2005, rec. 2639/2004). De hecho, en un principio, ajeno al concepto social de discapacidad, la Sala de lo Social del TS dicta varios pronunciamientos condicionando la existencia de una situación de discapacidad al reconocimiento formal, mediante «la declaración de minusválido» (sentencias del TS de 29 de enero de 2001, rec. 1566/2000, y de 22 de noviembre de 2007, rec. 3907/2006). La enfermedad no constituye, con carácter general, una causa de discriminación prohibida, en virtud del artículo 14 de la CE -salvo que exista un elemento de segregación ${ }^{4}-$, ni en particular en el ámbito laboral, de conformidad con el artículo 4.2 c) del ET; de ahí la necesidad de configurar un nuevo concepto de discapacidad, que permita dar respuesta a aquellas personas que padez-

${ }^{4}$ La sentencia del TC 62/2008, de 26 de mayo, aclara que existe tal elemento de segregación cuando la decisión se basa en «la mera existencia de la enfermedad en sí misma considerada o en la estigmatización como persona enferma de quien la padece». 
can una enfermedad, la cual, al interactuar con las diversas barreras existentes en la sociedad, dé lugar a una discapacidad.

Tras la interpretación efectuada por el TJUE en el asunto Chacón Navas, el JS n. 33 de Madrid (sentencia de 16 de octubre de 2006, rec. 641/2004) resuelve declarando la improcedencia del despido. El juzgado madrileño -partiendo de la necesaria distinción entre enfermedad y discapacidad-considera que si bien la actora demostró el padecimiento de una dolencia física, no consiguió acreditar «la probabilidad cierta de que sus limitaciones se iban a prolongar en el tiempo» y, por tanto, no se desplazó a la empresa la carga de probar la razonabilidad de su actuación. Existe, en definitiva, una continuidad de la línea jurisprudencial marcada por el TS. No obstante, es cierto que a raíz de los últimos pronunciamientos del TJUE, especialmente tras el asunto Daoudidi, ha tenido lugar una cierta flexibilización de esta postura, abriéndose la puerta a la posibilidad de considerar la nulidad del despido de un trabajador/a enfermo/a, por considerarse la existencia de una situación de discapacidad. Sin embargo, los tribunales españoles no han asumido la doctrina del TJUE de forma unívoca, lo que ha derivado en pronunciamientos judiciales dispares en cuanto a la calificación judicial del despido.

Por otro lado, se presentan especiales dificultades para la determinación del carácter duradero de la dolencia, ya que debido a la amplitud de los criterios sentados por el TJUE, es el juzgador nacional el que debe valorar este extremo caso por caso. Sin embargo, sí que se han ido consolidando una serie de parámetros en nuestra jurisprudencia laboral; entre ellos, la duración de la baja laboral por incapacidad temporal (IT), si bien no existe consenso respecto al concreto lapso temporal que cabe considerar como prolongado. En este sentido, para el TS y gran parte de la jurisprudencia menor, la existencia de una situación de IT de pocos días de duración no es acreedora de la condición de discapacidad, de modo que se ha tomado como referencia el agotamiento del plazo máximo de duración de la IT de 365 días (sentencias del TS de 3 de mayo de 2016, rec. 3348/2014, y del TSJ de Castilla y León, de 30 de noviembre de 2017, rec. 1828/2017). No obstante, no se trata de una postura pacífica en nuestros tribunales, existiendo pronunciamientos judiciales en los que se declara la nulidad del despido con base en una situación de enfermedad de corta duración.

A modo de ejemplo, cabe citar la sentencia del JS de Barcelona de 23 de diciembre de 2016 (rec. 1219/2014), en la que el juzgador considera que la patología padecida por el trabajador podía ser catalogada como de larga duración. Y ello, por entender que del resultado de la primera resonancia realizada se desprende que las lesiones del actor "hacían impensable una reincorporación a corto plazo, en especial la rotura del ligamento" (FD 38. ${ }^{\circ}$ ), lo que unido a la duración de la IT, que se prolongó hasta casi 10 meses, supone, a juicio del juez de instancia, que la limitación no "presentaba una perspectiva bien delimitada en cuanto a su finalización a corto plazo». Es importante destacar que esta sentencia fue revocada a su vez por la sentencia del TSJ de Cataluña de 12 de junio de 2017 (rec. 2310/2017), al entender que resta relevancia a la duración total de la IT, visto que, cuando tiene lugar el despido, solamente ha transcurrido un mes y medio desde el accidente, y tal y como había sentado el TJUE debe tenerse en cuenta el estado de incapacidad del 
interesado en la fecha en la que se adopta contra él el acto presuntamente discriminatorio 5 . La sentencia del JS de Cuenca de 29 de mayo de 2018 choca frontalmente con esta idea, en la medida en la que se califica como nulo el despido de una trabajadora atendiendo al riesgo de recaer en el cáncer de mama que había padecido en el pasado. La importancia de esta resolución radica en que, a diferencia de las anteriores resoluciones, para determinar si la actora ostenta o no la condición de discapacitada no se tiene tanto en cuenta su estado de salud actual, sino la probabilidad de que sufra en el futuro nuevos procesos de IT atendiendo a su historial médico. En esta misma línea, la sentencia del TSJ de Cantabria de 18 de enero de 2019 (rec. 833/2018) declara la nulidad del despido disciplinario de una trabajadora mientras se encuentra en situación de IT por padecer cáncer de útero. La Sala cántabra argumenta que, dado el impacto negativo que normalmente tiene el cáncer en la vida del individuo (sobre todo su tratamiento, que habitualmente conlleva cirugía, radiación o quimioterapia), se puede concluir que la dolencia de la trabajadora es de carácter duradero y que impedirá su participación plena y efectiva en la actividad profesional. En definitiva, existe una divergencia entre los criterios interpretativos que parecían estar sentados por nuestros tribunales, de modo que la duración de la IT no siempre resulta determinante a fin de calificar una dolencia como discapacidad.

Por otra parte, la sentencia del TS de 15 de marzo proporciona un nuevo criterio, cual es la existencia de resolución relativa a la duración en el futuro de la dolen$\mathrm{cia}^{6}$. En particular, argumenta aquí la Sala que «la situación de incapacidad temporal en la que se hallaba la trabajadora al ser despedida, fecha en la que ni siquiera había agotado el periodo máximo y mucho menos existía resolución alguna acerca de una situación duradera de futuro no permite identificarla con la noción de discapacidad distinta de "la enfermedad en cuanto tal"». Sin embargo, de nuevo, en la sentencia del JS de Mataró, de 20 de noviembre de 2017 (rec. 367/2017), se declara nulo el despido disciplinario de un trabajador que ha sufrido diversas crisis epilépticas, que han derivado en varios procesos de IT de corta y media duración. Si bien los procesos de IT sí tienen una duración bien delimitada (16 y 38 días), el hecho de que el empresario fuera conocedor de la enfermedad del actor, y que hubiese padecido 4 crisis en los últimos meses, precisando incluso de tratamiento médico, son indicios suficientes que permiten considerar que se trata de una dolencia de naturaleza duradera. No está de más señalar la existencia de cierta doctrina crítica con este fallo (De Heredia, 2017), por considerar que el último periodo de baja del trabajador (38 días) sí que está bien delimitado en el tiempo y por tanto no cabría encuadrar la situación del trabajador en el concepto de discapacidad. Claro que este argumento también podría oponerse, con arreglo a la propia jurisprudencia del TJUE

5 En sentido contrario, la sentencia del TSJ de País Vasco de 26 de septiembre de 2017 (rec. 1734/2017) toma en consideración la ampliación de la duración de la IT inicial acaecida con posterioridad al despido.

${ }^{6}$ En este mismo sentido, véase también la STSJ Cataluña, de 14 de enero de 2019 (rec. $5527 / 2018)$ 
(asunto Daoudidi), que, dentro del sistema de indicios que configura, no solo contempla el criterio que atiende a la falta de delimitación a corto plazo de la duración de la dolencia, sino que alternativamente también considera si dicha incapacidad puede prolongarse significativamente antes del restablecimiento de dicha persona. Por eso mismo, y atendiendo a la propia naturaleza de la enfermedad padecida por el trabajador, una epilepsia en tratamiento que ha derivado en cuatro crisis en un corto periodo de tiempo, permitiría aventurar la posibilidad de que la enfermedad se mantenga durante un largo periodo de tiempo.

La adopción por la empresa de ajustes razonables se configura también como uno de los aspectos esenciales que debe valorar el juzgador a fin de determinar si la decisión del empleador/a puede ser calificada o no como discriminatoria, por razón de la discapacidad de la persona trabajadora. En este sentido, resulta ineludible la cita de la sentencia del TS de 22 de febrero de 2016 (rec. 160/2016.), donde se niega la concurrencia de discriminación por razón de discapacidad cuando la empresa ha llevado a cabo diversas medidas de adaptación del trabajo a la enfermedad. Esta sentencia trae causa de la demanda interpuesta por una trabajadora a la que -tras sufrir un atraco con arma de fuego- se le diagnostica estrés postraumático, por lo cual sufre diversos procesos de IT, hasta que finalmente es despedida por ineptitud sobrevenida. El TS considera que la situación de la trabajadora puede ser calificada como de discapacidad y, por lo tanto, le son de aplicación todas las garantías que la Directiva prevé; entre ellas, la adopción de ajustes razonables. Ahora bien, dado que "por parte de la empresa, se llevaron a cabo distintas y sucesivas medidas todas ellas tendentes a la readaptación de la concreta situación de la actora a otros puestos de trabajo que pudieran minimizar las consecuencias de la afectación», la decisión empresarial no se considera aquí discriminatoria. Esta postura supone la completa asunción de la jurisprudencia europea, que concibe las medidas de ajuste como la consecuencia de la discapacidad, y no el elemento constitutivo, de modo que aquellas «son aplicables sólo a condición de que exista una discapacidad» (apdo. 46 de la sentencia del TJUE de 11 de abril de 2013). No obstante, algún autor mantiene lo contrario, sobre la base de que la adopción de medidas de ajuste o apoyo es el elemento constitutivo de la discapacidad, de modo que cabría extender el marco protector a los trabajadores/as enfermos/as que, aun no encajando en el concepto de discapacidad europeo, requieran unas concretas medidas de adaptación del puesto de trabajo, a fin de evitar que la interacción con las barreras existentes dé lugar a una situación de discapacidad (De Fuentes, 2016: 88, 89 y 90).

De la jurisprudencia analizada, se desprende que la duración de la IT es el factor principal a fin de calificar como discapacidad la situación del trabajador/a. Ahora bien, aunque es cierto que puede configurarse como un importante indicio de la durabilidad de la enfermedad, no conviene, a mi juicio, considerar este criterio en exclusiva, sino que debe ser integrado o complementado por otros. En efecto, no conviene olvidar su marcado carácter subjetivo, quedando condicionado a la valoración personal de cada juzgador. Además, la existencia de una resolución sobre la duración de la enfermedad en el futuro se erige como el otro pilar fundamental que debe ser valorado por el juzgador. Debido a la inconcreción del término «resolución", algún autor ha planteado si con dicho término se hace referencia a la existen- 
cia de una resolución administrativa de incapacidad, con el consecuente abandono del concepto funcional de discapacidad, retornándose a los orígenes del modelo médico (Olmos, 2019: 7). De las citadas resoluciones parece deducirse que en el término «resolución» cabe incluir la documentación médica de cualquier tipo que permita presumir que el trabajador no se recuperará a corto plazo.

A la luz de cuanto acaba de exponerse, podemos afirmar que los tribunales españoles parecen haberse decantado por una interpretación restrictiva de las bases sentadas por la jurisprudencia del TJUE. De ahí la conveniencia de la valoración de otros aspectos más allá de la mera extensión temporal, tales como los antecedentes médicos del individuo, la existencia con anterioridad de bajas por IT causadas por la misma enfermedad, así como el carácter crónico de la enfermedad, en la medida en la que los síntomas suelen repetirse de forma cíclica dando lugar a periodos de baja intermitentes. En este sentido, resulta irrelevante el hecho de que el trabajador/a se encuentre en situación de alta médica cuando es despedido. La jurisprudencia del TJUE ha supuesto el nacimiento de un nuevo concepto de discapacidad, dejando atrás aquella concepción en virtud de la cual el individuo debía padecer una limitación de carácter permanente e irreversible, inevitablemente ligada a la resolución administrativa que la reconociera como tal. Ahora, tal y como ha ido perfilando dicho tribunal, nos encontramos ante un concepto de discapacidad flexible (García, 2018: 87-88), el cual ha permitido dar amparo a aquellos/as trabajadores/as que -aun no teniendo un grado de discapacidad reconocido formalmente- presentan determinadas dolencias que, atendiendo a sus especiales características o duración, son merecedoras de la tutela antidiscriminatoria reforzada por razón de discapacidad.

\section{VALORACIÓN FINAL}

El marco jurídico vigente de protección de las personas con discapacidad deja patente la completa asunción en nuestro ordenamiento jurídico del modelo social, el cual pone su foco de atención en la existencia de barreras en la sociedad que impiden la participación plena y efectiva del individuo, en igualdad de condiciones que el resto de la ciudadanía. Pese a que debemos partir de la necesaria distinción entre enfermedad y discapacidad - por tratarse de fenómenos completamente distintos-, la reciente jurisprudencia de la Unión Europea se ha hecho eco de la necesidad de configurar un nuevo concepto de discapacidad que dé respuesta a los trabajadores/as que, aun no considerándose integrados en el colectivo de personas con discapacidad, con el correspondiente reconocimiento formal, sean acreedores de esta tutela jurídica reforzada en el ámbito laboral, y ello a fin de evitar que determinadas barreras sociales los coloquen en una situación de desventaja particular. En definitiva, ha cambiado el modo tradicional de entender el fenómeno de la discapacidad, y en consonancia con ello deben centrarse los esfuerzos en la adopción de medidas de adaptación del puesto de trabajo, incluso con carácter previo a la aparición de la situación de discapacidad. 


\section{BIBLIOGRAFÍA}

Carrasquero, M. (2018). «Los ajustes razonables para personas con discapacidad en la Unión Europea». Revista de Estudios Europeos, 71: 38-47.

De Fuentes García, C. (2016). «Sobre el concepto jurídico de persona con discapacidad y la noción de apoyos necesarios». Revista Española de Discapacidad, 4(2): 81-99.

De Heredia, I. (2016). Caso Daouidi (TJUE): incapacidad temporal, despido y discriminación (en línea), recuperado de https://ignasibeltran.com/2016/12/02/caso-daouidi-tjue-incapacidad-temporal-despido-y-discriminacion/. Último acceso 25 de marzo de 2020.

De Heredia, I. (2017). Extinción injustificada durante incapacidad temporal: 3 nuevos casos de nulidad ('ex' Daouidi) y 4 de improcedencia (en línea), recuperado de https://ignasibeltran. com/2017/12/27/extincion-injustificada-durante-incapacidad-temporal-3-nuevos-casos-de-nulidad-ex-daouidi-y-4-de-improcedencia/. Último acceso 4 de abril de 2020.

De Heredia, I. (2019). Despido objetivo por faltas de asistencias y el caso Ruiz Conejero: el TSJ de CLM ratifica la existencia de discriminación indirecta (en línea), recuperado de https:// ignasibeltran.com/2019/04/26/despido-objetivo-por-faltas-de-asistencias-y-el-caso-ruiz-conejero-el-tsj-de-clm-ratifica-la-existencia-de-discriminacion-indirecta/. Último acceso 10 de abril de 2020.

García, A. (2018). Necesidades especiales de apoyo laboral en colectivos con discapacidad. En particular el empleo protegido. Pamplona: Aranzadi.

García, A. (2019). «El Tribunal Supremo vuelve a establecer la necesaria distinción entre discapacidad e incapacidad permanente laboral». Revista Española de Derecho del Trabajo, 221: 171-188.

Gutiérrez, D. (2015). «La obligación de realizar ajustes razonables del puesto de trabajo a personas con discapacidad en EE. UU. y España: una visión comparada». Revista Internacional y Comparada de Relaciones Laborales y Derecho del Empleo, 3: 32-63.

Olmos, I. (2019). «El despido en situación de incapacidad temporal, la enfermedad y la discapacidad». Nueva revista Española de Derecho del Trabajo, 217: 75-98.

Pérez, J. (2015). Contratación laboral de personas con discapacidad. Incentivos y Cuotas de reserva, Pamplona: Thomson Reuters.

Pérez, L. (2012). La Configuración jurídica de los ajustes razonables (en línea), recuperado de https://www.cermi.es/sites/default/files/docs/novedades/LA_CONFIGURACI_N_JUR_ DICA_DE_LOS_AJUSTES_RAZONABLES.pdf. Último acceso 18 de marzo de 2020.

Rodríguez SANZ, B. (2014). «La obligación de realizar ajustes razonables del puesto de trabajo a las personas con discapacidad». Revista Temas Laborales, 127: 85-120.

Rojo, E. (2019). El TSJ de Castilla-La Mancha confirma que existe discriminación cuando se procede al despido de un trabajador por bajas en el trabajo que derivan de su estado de discapacidad. Notas a la sentencia de 10 de abril de 2019, y recordatorio de las sentencias del TJUE y del JS (en línea), recuperado de http://www.eduardorojotorrecilla.es/2019/04/el-tsj-de-castillala-mancha-confirma.html. Último acceso 6 de abril de 2020. 